\title{
Cordycepin Triphosphate
}

National Cancer Institute

\section{Source}

National Cancer Institute. Cordycepin Triphosphate. NCI Thesaurus. Code C967.

The triphosphate salt of cordycepin, a purine nucleoside antimetabolite and antibiotic isolated from the fungus Cordyceps militaris with potential antineoplastic, antioxidant, and anti-inflammatory activities. Cordycepin is an inhibitor of polyadenylation, activates AMP-activated protein kinase (AMPK), and reduces mammalian target of rapamycin (mTOR) signaling, which may result in both the induction of tumor cell apoptosis and a decrease in tumor cell proliferation. MTOR, a serine/threonine kinase belong ing to the phosphatidylinositol 3-kinase (PI3K)-related kinase (PIKK) family, plays an important role in the PI3K/AKT/mTOR signaling pathway that regulates cell growth and proliferation, and its expression or activity is frequently dysregulated in human cancers. 